\title{
Joining of Soda Lime Silicate Glass to Dissimilar Ti-304L Metal Joint by Heat Treatment in Air
}

\author{
M.B. Telli* AND H.G. SANLI \\ Kocaeli University, Metallurgical and Materials Engineering, Kocaeli, Turkey
}

\begin{abstract}
In this work, soda lime silicate glass was joined to powder metallurgically prepared Ti-304L joint with a heat treatment in air. Ti interlayer was oxidized fast and $\mathrm{TiO}_{2}$ layer formed at joining interface. For the used sample size and dimensions, joined glass did not fracture but delaminated from failing $\mathrm{TiO}_{2}$ layer. While developed residual stress levels were not very high (up to $150 \mathrm{MPa}$ ) for joined glass, the formed $\mathrm{TiO}_{2}$ layer was exposed to very high residual stress levels (up to $550 \mathrm{MPa}$ ). Thus, glass layer was debonded from failing $\mathrm{TiO}_{2}$ layer where high residual stress levels observed. Formed $\mathrm{TiO}_{2}$ layer also reacted with joined glass, leading to some gas bubble defects at the joined glass interface. For successful joining, formation of $\mathrm{TiO}_{2}$ layer and its residual stress levels were found to be important.
\end{abstract}

DOI: 10.12693/APhysPolA.135.653

PACS/topics: glasses, scanning electron microscopy (SEM) (including EBIC), computer modeling and simulation

\section{Introduction}

Heat collecting units of parabolic solar collectors require glass to metal joining to improve heat collecting efficiency $[1,2]$. Borosilicate glass and Kovar alloy are commonly considered, due to their similar thermal expansion coefficients, to lower residual stresses [2-4]. However, if 304L stainless steel could be used instead of expensive Kovar alloy, it would be more economical as an alternative joining. Due to relatively higher thermal expansion coefficient of 304L $\left(18.7 \mu \mathrm{m} /\left(\mathrm{m}^{\circ} \mathrm{C}\right)\right)$ than borosilicate glass $\left(3.25 \mu \mathrm{m} /\left(\mathrm{m}^{\circ} \mathrm{C}\right)\right)$, direct joining of $304 \mathrm{~L}$ to borosilicate glass is difficult. Therefore, use of an intermediate layer having both good bonding to 304L and glass, and thermal expansion coefficient, similar to joined glass, to lower residual stresses, is required. Titanium was shown to be joined to 304L by powder metallurgical uniaxial pressing if residual stress levels were kept low in earlier study [5]. Titanium was also illustrated to be joined to soda lime silicate glass in air ambient due to their close thermal expansion coefficients of titanium $\left(10.1 \mu \mathrm{m} /\left(\mathrm{m}^{\circ} \mathrm{C}\right)\right)$ and soda lime silicate glass $\left(9.1 \mu \mathrm{m} /\left(\mathrm{m}^{\circ} \mathrm{C}\right)\right)[6]$. Therefore, it could be possible to join $304 \mathrm{~L}$ to soda lime silicate glass by using titanium as an intermediate layer. In this study, soda lime silicate glass to powder metallurgically pre-joined Ti-304L in air, using controlled heat treatment, is investigated.

\section{Experimental procedure}

Soda lime silicate glass (Schott Ar-Glass) was joined to powder metallurgically prepared Ti-304L joint in air. Ti-304L dissimilar joint Ti-304L joint having diameter of $20 \mathrm{~mm}$ and thickness of $1 \mathrm{~mm}$ for $\mathrm{Ti}$ and $1.5 \mathrm{~mm}$ for

\footnotetext{
* corresponding author; e-mail mustafa.telli@kocaeli.edu.tr
}

304L layer was prepared first by pressing their powders at $1000^{\circ} \mathrm{C}$ for $10 \mathrm{~min} \mathrm{[5].} \mathrm{Glass} \mathrm{with} 10 \mathrm{~mm}$ diameter and $1.25 \mathrm{~mm}$ thickness was placed on Ti-304L disc and heat treated at $800^{\circ} \mathrm{C}$ for 5 min by inserting in preheated oven in air. The joined sample was cooled down to $550^{\circ} \mathrm{C}$ for $20 \mathrm{~min}$, and then thermally annealed for $20 \mathrm{~min}$ to remove any prior residual stresses developed in glass layer. Sample was then cooled down to room temperature for $3 \mathrm{~h}$. Glass to Ti/304L joining interface was investigated by employing a JEOL6060 model scanning electron microscope (SEM). Residual stresses were modelled by employing ANSYS 14 Multiphysics Software and were considered to be developing due to cooling down of joined layers having different material properties (Table I) from $550{ }^{\circ} \mathrm{C}$ to room temperature. In modeling, $\mathrm{TiO}_{2}$ layer and glass were considered as brittle elastic materials, but $\mathrm{Ti}$ and 304L layers were considered as both elastic and plastic materials.

TABLE I

Materials properties used for residual joining stress calculations: $\alpha$ - thermal expansion coefficient, $E$ - Young modulus, $v$ - Poisson ratio, $\sigma_{y}$ - yield strength, $\sigma_{\text {True }}$ — true stress level, $\varepsilon_{\text {True }}$ — true strain level.

\begin{tabular}{l|c|c|c|c}
\hline \hline \multicolumn{1}{c|}{ Property } & Glass & $\mathrm{TiO}_{2}$ & $\mathrm{Ti}$ & $304 \mathrm{~L}$ \\
\hline$\alpha[\mu \mathrm{m} / \mathrm{m}]$ & 9.1 & 8.9 & 10.1 & 18.7 \\
$E[\mathrm{GPa}]$ & 73 & 287 & 116 & 193 \\
$v$ & 0.22 & 0.27 & 0.34 & 0.24 \\
$\sigma_{y}[\mathrm{MPa}]$ & & & 240 & 280 \\
$\sigma_{\text {True }}[\mathrm{MPa}]$ & & & 550 & 1700 \\
$\varepsilon_{\text {True }}[\mathrm{m} / \mathrm{m}]$ & & & 0.2 & 1.15
\end{tabular}

\section{Results and discussion}

Figure 1 shows that joining of soda lime silicate glass to $\mathrm{Ti} / 304 \mathrm{~L}$ layer was possible without fracturing or complete debonding of glass. However, titanium layer was oxidized fast and was subjected to reaction with joined glass with a heat treatment at $800^{\circ} \mathrm{C}$ for $5 \mathrm{~min}$ in air. 


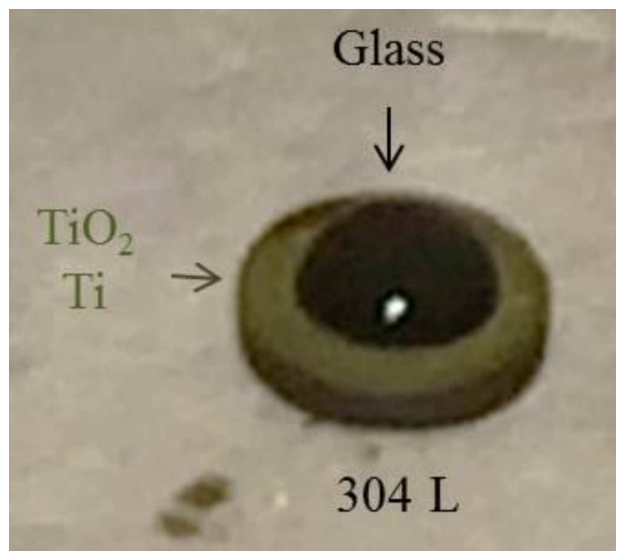

Fig. 1. Soda lime silicate glass joined to $\mathrm{Ti} / 304 \mathrm{~L}$ at $800{ }^{\circ} \mathrm{C}$ for $5 \mathrm{~min}$ in air.

Figure 2 illustrates that soda lime silicate glass was partially debonding from $\mathrm{Ti} / 304 \mathrm{~L}$ layer. Glass debonding was occurring within formed thin $\mathrm{TiO}_{2}$ layer and was observed mostly towards the outer edge of glass layer. This suggests that $\mathrm{TiO}_{2}$ layer formed at debonding region had high residual stress levels enough to fail. There was also some bubble formation in glass layer due to chemical reaction between formed $\mathrm{TiO}_{2}$ and glass.
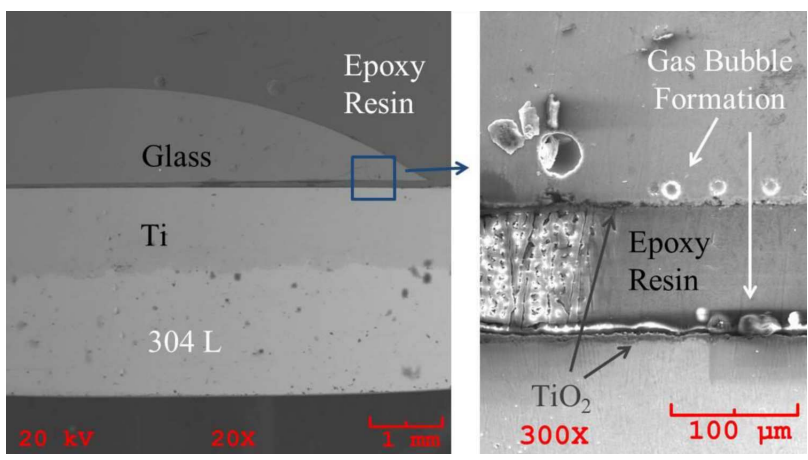

Fig. 2. Scanning electron microscope images of glass/Ti/304L joining cross-section and glass debonding region at higher magnification.

Figure 3 presents modelled maximum principal residual stress levels developed at joined layers for the studied sample size and shape. Residual stress at joined glass layer was not very high and at most of the order of $150 \mathrm{MPa}$, observed at upper region of glass. This agreed well with observation of no fracture of glass layer. On the contrary, residual stress on formed $\mathrm{TiO}_{2}$ layer could be quite high such as, of the order of $550 \mathrm{MPa}$, observed towards outer glass $/ \mathrm{TiO}_{2} / \mathrm{Ti}$ joining edge, but dropped to $-40 \mathrm{MPa}$ at central region. This result also agreed well with experimental observation of not seeing complete debonding and observation of debonding of glass layer mainly towards outer joining edge within $\mathrm{TiO}_{2}$ layer.

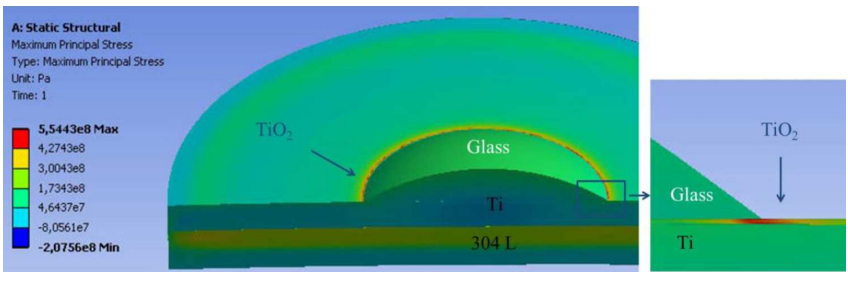

Fig. 3. ANSYS 14 Multiphysics modelling results of maximum principal residual stress levels at joined layers.

When $\mathrm{TiO}_{2}$ layer was exposed to high residual stress levels at the order of $550 \mathrm{MPa}$, joined glass was found to be debonding due to failure of $\mathrm{TiO}_{2}$ layer. Therefore, formation of $\mathrm{TiO}_{2}$ layer and its residual stress levels were important and needed to be minimized for successful joining.

\section{Conclusion}

Soda lime silicate glass was joined 304L joint by using titanium as interlayer with a heat treatment in air at $800^{\circ} \mathrm{C}$ for $5 \mathrm{~min}$. For the used sample dimensions and size, developed residual stress on glass was not very high (of the order of $150 \mathrm{MPa}$ at most) and did not cause fracture of joined glass. However, $\mathrm{TiO}_{2}$ layer was formed with a heat treatment in air. $\mathrm{TiO}_{2}$ layer could be exposed to very high residual stress levels (at the order of $550 \mathrm{MPa}$ ) which is observed towards the edge of glass joining. This caused failure of $\mathrm{TiO}_{2}$ layer and debonding of glass layer from $\mathrm{Ti} / 304 \mathrm{~L}$. Formation of $\mathrm{TiO}_{2}$ layer and residual stress levels developing on this layer needs to be considered and minimized for successful joining.

\section{Acknowledgments}

This study was financially supported by scientific research project 2014-87 of Kocaeli University, Turkey.

\section{References}

[1] W.J. Malfait, R. Klemencic, B. Lang, T. Rist, M. Klucka, Z. Zajacz, M.M. Koebel, J. Mater. Process. Technol. 236176 (2016).

[2] D.Q. Lei, Z.F. Wang, J. Li, J.B. Li, Z.J. Wang, Renew. Energ. 48, 85 (2012).

[3] C. Chanmuang, M. Naksata, H. Jain, C.E. Lyman, Mater. Sci. Eng. 474, 218 (2008).

[4] D. Lei, Z. Wang, J. Li, Mater. Des. 31, 1813 (2010).

[5] M.B. Telli, R. Yamanoğlu, H.G. Sanll, Acta Phys. Pol. A 34, 37 (2018).

[6] M.B. Telli, Acta Phys. Pol. A 131, 414 (2017). 